\title{
A State of De-Stress: Examining the Relationship Between Subjective Well-Being, Self-Compassion, and Empathy
}

\author{
Kurt Hablado \\ Department of Psychology, Mount Royal University, Calgary, Canada \\ Mitchell Clark \\ Department of Psychology, Mount Royal University, Calgary, Canada;
}

\begin{abstract}
University can be a period of stress caused by academic, social, or personal demands. Yet most are able to rise above the adversity and grow from their experiences. Research on stress has found that a negative association exists with subjective well-being broadly conceptualized as life happiness (Denovan \& Macaskill, 2017; Zhang, 2009). There are also positive relationships demonstrated between selfcompassion and empathy with subjective well-being (Bluth et al., 2016; Thomas et al., 2007). This study examined the relationship between perceived stress and subjective well-being in a non-clinical university population. The study also examined the relationship between stress and subjective well-being, and how that relationship was moderated by the self-compassion and mediated by empathy.
\end{abstract}

Keywords: Stress, Subjective well-being, Self-compassion, Empathy, Postsecondary

\section{INTRODUCTION}

University can be a period of personal growth, but it can also be a stressful time for many students. According to Friedlander, Reid, Shupak, and Cribbie (2007), the transition from high school to university observed an increase in academic demands, leaving many individuals to question whether they were able to meet them. Previous studies (Dwyer \& Cummings, 2001; Bayram \& Bilgel, 2008) have also established that there was a marked decrease in academic performance and an increase in psychological distress when students were unable to cope with these demands.

One possible reason that students are able to overcome their exposure to stressors and graduate from university could be attributed to specific personality traits. Past research (Neff, Kirkpatrick, \& Rude, 2007) has shown that self-compassion in particular may play a role in managing stress. Additionally, one study found links between empathy and subjective well-being, as highly empathetic individuals reported higher levels of life satisfaction and happiness compared to those with lower levels of empathy (Wei, Liao, Ku, \& Shaffer, 2011). The current research sought to examine the role of stress on subjective well-being. Additionally, the moderating effects of selfcompassion and the mediating effects of cognitive and affective empathy were also investigated. 


\section{Stress and Subjective Well-Being}

Subjective well-being (SWB) can be thought of as a broad concept consisting of happiness, life satisfaction, and affect (Myers \& Diener, 1995). Examination of SWB looks at three domains: affect (mood and emotions), cognitive evaluations of general life satisfaction, and evaluations of specific life domains (Diener, Suh, Lucas, \& Smith, 1999; International Wellbeing Group, 2013). Bradburn and Caplovitz (1965) state that affect is comprised of two components: the presence of positive mood and the relative absence of negative mood (as cited in Diener et al., 1999). The second domain of SWB examines an individual's satisfaction with their life as a whole. This evaluation of general life satisfaction is linked with the third domain: evaluation of specific life domains such as standard of living, health, life achievement, and personal relationships (International Wellbeing Group, 2013). By using this approach, the International Wellbeing Group (2013) believes researchers are able to establish a baseline to which they can further compare the specific life domains that contribute to an individual's general sense of life satisfaction.

Research conducted on the effects of stress on SWB, particularly with college and university students, has found a consistently negative relationship (Denovan \& Macaskill, 2017; Cooke, Bewick, Barkham, Bradley, \& Audin, 2006; Bayram \& Bilgel, 2008). Specifically, first-year university students report lower life satisfaction and optimism, as well as higher levels of anxiety and depression during periods of academic stress (Denovan \& Macaskill, 2017; Bayram \& Bilgel, 2008). These results may be further explained by the findings of Cooke and colleagues (2006) who found that that the reported well-being of first-year students was lowest at the beginning of the semester but gradually improved, suggesting students acclimate to the stress over time.

\section{Stress and Self-Compassion}

Neff (2003a) described self-compassion as having three inherent components: self-kindness versus self-judgment, common humanity versus isolation, and mindfulness versus overidentification. Selfkindness has been defined by past researchers as being compassionate and caring towards oneself when faced with difficult times (Wei et al., 2011). By contrast, self-judgment behaviors consist of criticizing or berating oneself following difficulty or failure (Neff, 2003b). According to Brown (1999), when an individual engages in self-judgment, their feelings of self-consciousness increase, and feelings of isolation occur as a result (as cited in Neff, 2003b). Therefore, Fromm (1963) proposed that engaging in self-kindness is crucial for mitigating feelings of self-consciousness (as cited in Neff, 2003b).

The second component of self-compassion is common humanity versus isolation. Common humanity requires an understanding that life's difficulties happen to everyone and are an inherent part of the human condition (Wei et al., 2011). Failing is a part of human nature and we should ensure we are not fixated on the idea that we are alone throughout our failure or difficulties at any given time.

The final component of self-compassion looks at mindfulness versus overidentification, and requires individuals to be aware, but not fixated, on their pain and suffering when faced with difficulty (Wei et al., 2011). For individuals going through a difficult event, mindfulness allows them to recognize and acknowledge all they are feeling. By contrast, the inability to engage in mindfulness will result in over-identification. When we over-identify with our failures or difficult events, we 
Hablado, K., \& Clark, M. (2020) A State of De-Stress: Examining the Relationship Between Subjective Well-Being, Self-Compassion, and Empathy. Advances in Social Sciences Research Journal, 7(5) 412-426.

become completely absorbed or fixated on them and this hinders our ability to maintain perspective.

There has been considerable evidence on self-compassion that demonstrates links to reduced responses to stress (Breines et al., 2015; Bluth et al., 2016) and reduced reactions to unpleasant life events (Leary, Tate, Adams, Allen, \& Hancock, 2007). In studies using survey data (Finlay-Jones, Rees, \& Kane, 2015; Leary et al., 2007) participants reported a negative relationship between selfcompassion and stress, in which higher levels of self-compassion were related to lower levels of stress. In studies using laboratory tests, participants who reported higher levels of self-compassion demonstrated an overall lower physiological response to stressors compared to their peers with lower levels of self-compassion (Breines et al., 2015; Bluth et al., 2016). According to Finlay-Jones and colleagues (2015), engaging in self-compassion can lead to an increased engagement in selfacceptance and positive self-worth - especially in the face of adversity or negative events. Research by Leary and colleagues (2007) has also suggested that self-compassion has the ability to mitigate reactions to any distressing event involving failure, rejection, or embarrassment.

Taken altogether, these findings demonstrate an inverse relationship between stress and selfcompassion and lends support towards the idea that having self-compassion is beneficial for mitigating feelings or stress. Thus, being able to further develop self-compassion as a trait or coping strategy may be especially helpful for reacting to stressors in the future.

\section{Stress and Empathy}

Empathy can be defined as "a complex suite of psychological processes experienced when people take the perspective of another person" (Welp \& Brown, 2014) and is comprised of a cognitive and affective component (Davis, 1983). According to Decety \& Jackson (2006), the cognitive component involves the ability to know another person's inner experiences and the reasons for why the individual feels that way, whereas the affective component of empathy is the ability to identify the feelings or emotions of another person (as cited by Thoma et al., 2011).

There is some complexity when it comes to the relationship between stress and empathy. Some researchers (Park et al., 2015; Duarte, Pinto-Gouveia, \& Cruz, 2016) have found a significant negative relationship, indicating that those who reported higher levels of stress also reported having lower levels of empathy. One explanation offered for this relationship was burnout, defined as "a work-related syndrome characterized by emotional exhaustion, cynicism, and depersonalization, as well as reductions in personal accomplishment and effectiveness" (Brazeau, Schroeder, Rovi, \& Boyd, 2010). The results from both studies indicate that as levels of stress increase, levels of empathy decrease.

Conversely, one study conducted by Wolf and colleagues (2015) demonstrated that the burnout explanation may not be applicable for all instances. In response to psychosocial stress in the laboratory, participants took a test of empathy. Participants who were stressed scored higher in affective, but not cognitive, empathy compared to the control group. These results suggest there is no straightforward relationship between stress and empathy, and that there may be other factors at play that explain how empathy is affected by stress. 


\section{The Present Study: Self-Compassion, Empathy, and Subjective Well-Being Self-compassion and subjective well-being.}

When individuals engage in self-compassion, they open themselves up to their own suffering rather than avoiding or disconnecting from it (Neff, 2003b). Intuitively, one may believe that engaging in this behavior could lead to feeling a lower SWB because of the confrontation with one's failures or difficulties. However, Neff (2003b) argued that when done properly, engaging in this open awareness can actually lead to a desire to alleviate one's suffering and heal one's self with kindness. Furthermore, engaging in self-compassion would open the individual up to nonjudgmental understanding with one's pain and help the individual realize that they are part of the common human experience (Neff, 2003b). As a result, practicing self-compassion may result in enhanced feelings of compassion and concern for other people because the individual is able to view another's experience without judgment and ultimately feel a sense of connection (Neff, 2003b).

There has been some research (Allen, Goldwasser, \& Leary, 2012; Wei et al., 2011; Bluth et al., 2016; Neely, Schallert, Mohammed, Roberts, \& Chen, 2009; Zessin, Dickhäuser, \& Garbade, 2015) in recent years that has examined and demonstrated a positive relationship between self-compassion and SWB. In aging adults, self-compassion was shown to moderate the relationship between physical pain and life satisfaction, suggesting that self-compassion may mitigate the effects of pain on individual life happiness (Allen, Goldwasser, \& Leary, 2012). Additionally, a meta-analysis by Zessin, Dickhäuser, and Garbade (2015) has found that there may be evidence for a causal effect of selfcompassion on well-being. Despite the abundance of research that examines the relationship between self-compassion and subjective well-being, no study was known to the researchers that examined the moderating effect of self-compassion on stress and SWB. The following study sought to address this gap in the literature.

Hypothesis 1. Higher stress led to lower SWB and this relationship is stronger for individuals lower in self-compassion compared to individuals higher in self-compassion.

\section{Empathy and subjective well-being.}

Little research has examined the direct relationship between empathy and SWB, but what does exist yielded positive results. In a college and community adult population, a significantly positive relationship between emotional empathy and self-compassion was found (Wei et al., 2011), indicating that higher levels of empathy were related to higher levels of SWB. Other studies (Bourgault et al., 2015; Shanafelt et al., 2005) have found similar results looking at the relationship between well-being and cognitive empathy in the medical profession. One explanation for why this association occurs is offered by Mehrabian (2000), who believed that having empathy towards others may "enhance emotional well-being, interpersonal relationships, and life success" (as cited by Wei et al., 2011). Furthermore, if an individual could display empathy to others, the recipients would feel gratitude and create feelings of connectedness, happiness, and positive affect (Wei et al., 2011), which would ultimately enhance SWB. However, recent research by Carnicer and Calderón (2013) argued that too much empathy for others may put people at risk for higher levels of psychological distress. Results showed that those who scored high in psychological distress on the Brief Symptom Inventory also scored significantly higher on emotional stress (Carciner \& Calderón, 2013). These findings suggest that becoming too involved with the problems of others could have negative effects on SWB. This relationship may be explained by Batson (1991), who believed it was integral to maintain a distinction between one's own feelings and that of another person's because 
Hablado, K., \& Clark, M. (2020) A State of De-Stress: Examining the Relationship Between Subjective Well-Being, Self-Compassion, and Empathy. Advances in Social Sciences Research Journal, 7(5) 412-426.

an inability to do so can contribute to "reduced empathic concern and increased personal distress" (as cited in Thoma et al., 2011). The present study sought to further explore the relationship between cognitive and affective empathy and subjective well-being. The second hypothesis proposed that:

Hypothesis 2. Higher stress is associated with lower SWB, and this relationship is explained better by lower levels of affective and cognitive empathy versus higher levels of affective and cognitive empathy.

\section{Participants}

METHOD

A total of 208 participants were recruited from the introductory psychology participant pool at Mount Royal University. The age of participants ranged from 17 to 43 years old $(\mathrm{M}=20.85, \mathrm{SD}=$ 3.86) and consisted of 152 females, 51 males, and 5 other/undisclosed genders. The sample primarily consisted of first-year students (64.4\%). Students who participated in the research contributed an hour of their time to complete the surveys and were subsequently granted a $1 \%$ course credit towards their introductory psychology class. For ease of access, the survey was posted online but participants were required to complete it in one sitting.

\section{Materials}

A total of seven surveys were posted on the online survey platform SurveyMonkey including the Self-Compassion Scale (SCS; Neff, 2003a), the Questionnaire of Cognitive and Affective Empathy (QCAE; Reniers, Corcoran, Drake, Shryane, \& Völme, 2011), the Perceived Stress Scale (PSS; Cohen, Kamarck, \& Mermelstein, 1983), the University Stress Scale (USS; Stallman, 2008), the Personal Wellbeing Index for Adults (PWI-A; International Wellbeing Group, 2013), the Student Life Satisfaction Scale (SLSS; Huebner, 1991), and the Positive and Negative Affect Schedule (PANAS; Watson, Clark, \& Tellegen, 1988). Participants were first asked to fill out a demographic form for age, gender, year of study, and program of study. After completing the demographic form, participants were then asked to complete the seven surveys. To control for order effects, the surveys were presented in a randomized sequence.

\section{Self-Compassion Scale}

The SCS is a scale developed by Neff (2003a) to measure an individual's level of self-compassion. It consists of 26 questions that explore the three inherent domains that comprise self-compassion: self-kindness versus self-judgment, common humanity versus isolation, and mindfulness versus over-identification (Neff, 2003a). Responses are measured on a 5-point Likert scale ranging from 1 (almost never) to 5 (almost always), with higher scores representing higher levels of selfcompassion. An example item from the SCS is "I try to be loving towards myself when I'm feeling emotional pain." Neff (2003a) reports a Cronbach's alpha of .92, indicating excellent internal consistency.

\section{Questionnaire of Cognitive and Affective Empathy}

The QCAE is a scale developed by Reniers and colleagues (2011) that assesses the domains of cognitive and affective empathy. The scale consists of 31 questions that measure responses on a 4point Likert scale ranging from 1 (strongly disagree) to 4 (strongly agree). According to Reniers and colleagues (2011), this 4-point Likert scale forces participants to make a choice as they are not 
presented with an option of "neither agree nor disagree." Items from the QCAE were derived from various other measures of empathy such as the Empathy Quotient (Baron-Cohen et al., 2003), the Hogan Empathy Scale (Hogan, 1969), the Empathy subscale of the ImpulsivenessVenturesomeness-Empathy Inventory (IVE; Eysenck \& Eysenck, 1978) and the Interpersonal Reactivity Index (Davis, 1983) with permission from their respective authors Reniers et al., 2011). An example question from the QCAE is "Before criticizing somebody, I try to imagine how I would feel if I was in their place." Reniers and colleagues (2011) report a Cronbach's alpha ranging from .65 to .85 , indicating questionable to good internal consistency.

\section{Perceived Stress Scale}

The PSS is a 14-item scale developed by Cohen, Kamarck, and Mermelstein (1983) to measure subjective levels of stress in one's life. It is intended to assess the degree to which one finds their life "unpredictable, uncontrollable, and overloading" (Cohen, Kamarck, \& Mermelstein, 1983). Participants are asked to rate their levels of stress within the last month on a 5-point Likert scale ranging from 0 (never) to 4 (very often), with higher scores indicating higher levels of perceived stress. An example of an item from the PSS is "In the last month, how often have you felt confident about your ability to handle your personal problems?" A review of the PSS conducted by Lee (2012) reported a Cronbach's alpha of .70, indicating acceptable internal consistency.

\section{University Stress Scale}

The USS is a 21-item scale developed by Stallman (2008) to measure levels of stress for university students. It uses a 4-point Likert scale ranging from 0 (not at all) to 3 (constantly) to measure the degree to which certain items cause the individual stress, with higher scores indicating higher levels of stress. Some example items that participants are asked to rate are academic/coursework demands, friendships, and study/life balance. Stallman and Hurst (2016) reported a Cronbach's alpha of .83, indicating good internal consistency.

\section{Student's Life Satisfaction Scale}

The SLSS is a 7-item scale developed by Huebner (1991) to measure an individual's overall satisfaction with her life. The SLSS uses a 6-point Likert scale ranging from 1 (strongly disagree) to 6 (strongly agree), with higher scores indicating higher levels of overall life satisfaction. One example item from the scale is "My life is better than most kids." Huebner (1991) reports a Cronbach's alpha of .82, indicating good internal consistency.

\section{Personal Wellbeing Index for Adults}

The PWI-A is a 7-item scale developed by the International Wellbeing Group (2013) to measure an individual's satisfaction with specific domains in her life. The PWI-A uses an 11-point Likert scale ranging from 0 (no satisfaction) to 10 (completely satisfied), with higher scores indicating higher levels of life satisfaction with that specific domain. Some examples of items that participants will be asked about are their satisfaction with their standard of living, health, and personal relationships. The International Wellbeing Group (2013) reports a Cronbach's alpha of .7 to .85, indicating acceptable to good internal consistency.

\section{Positive and Negative Affect Schedule}

The PANAS is a 20-item scale developed by Watson, Clark, and Tellegen (1988) that measures the extent to which the individual has experienced both positive and negative mood within the last 
Hablado, K., \& Clark, M. (2020) A State of De-Stress: Examining the Relationship Between Subjective Well-Being, Self-Compassion, and Empathy. Advances in Social Sciences Research Journal, 7(5) 412-426.

week. It uses a 5-point Likert scale that ranges from 1 (very slightly or not at all) to 5 (extremely). Higher scores on the Positive Affect items indicate higher levels of positive affect or mood. Similarly, higher scores on the Negative Affect items indicate higher levels of negative affect or mood. Some examples of positive items on the scale are Interested, Excited, and Determined. Some examples of negative items are Distressed, Upset, and Jittery. Watson, Clark, and Tellegen (1988) report a Cronbach's alpha for the positive affect items as .86 to .90, indicating good to excellent internal consistency. They also report a Cronbach's alpha for the negative affect items as .84 to .87 indicating good internal consistency.

\section{Procedure}

The study was conducted through an online survey via SurveyMonkey. After participants from the introductory psychology student pool signed up for the study, they were redirected to SurveyMonkey and presented with a consent form. Consent was obtained by clicking a button labelled I ACCEPT. If participants did not consent and instead hit the I DECLINE button, they were still granted the credit and given the opportunity to complete the study, but their data was automatically excluded. After providing consent, participants were asked to fill out a short 4question demographic form regarding their age, gender, current program of study, and their year of study. Following the demographic, participants were asked to complete the seven surveys. A debriefing form was presented, and a 1\% course credit was automatically granted regardless of completion.

\section{RESULTS}

For the first research question, the predicted moderator variable was self-compassion, which was measured through the Self-Compassion Scale (SCS; Neff, 2003a). For the second research question, the predicted mediator variable was empathy, which was measured through the Questionnaire of Cognitive and Affective Empathy (QCAE; Reniers et al., 2011). For both research questions, stress was the predictor variable and was measured through both the Perceived Stress Scale (PSS; Cohen, 1983) and the University Stress Scale (USS; Stallman, 2008). Subjective well-being was the outcome variable and was measured through the Personal Wellbeing Index (PWI; Personal Wellbeing Group, 2013), Student Life Satisfaction Scale (SLSS; Huebner, 1991), and the Positive and Negative Affect Schedule (PANAS; Watson, Clark, \& Tellegen, 1988). To calculate an overall measure of SWB, scores from the PWI, SLSS, and PANAS were converted to z-scores and combined. To calculate an overall stress score, results from the PSS and USS were converted to z-scores and combined.

Two hundred and eight students consented to the study by hitting 'I ACCEPT' on the online consent form. Missing data were treated using a series mean substitution for each question. Reported means, medians, and standard deviations for each scale are listed in Table 1. Bivariate correlations were calculated between stress, SWB, self-compassion, and empathy to determine the nature of the relationships. Regression analyses were calculated to examine the moderating effect of selfcompassion and the mediating effect of empathy on the relationship between stress and SWB. To reduce the risk of committing a Type I error, a Bonferroni correction was applied. 
Table 1. Calculated raw means and standard deviations from each measure.

\begin{tabular}{|c|c|c|c|c|c|}
\hline Scale & Mean & Median & SD & Min. & Max. \\
\hline Perceived Stress Scale & 20.94 & 21.00 & 6.71 & 4.00 & 39.00 \\
\hline University Stress Scale & 21.25 & 20.50 & 8.87 & 2.00 & 51.00 \\
\hline Personal Wellbeing Index & 47.85 & 49.00 & 11.07 & 12.00 & 70.00 \\
\hline Student Life Satisfaction Scale & 22.17 & 22.00 & 3.50 & 9.00 & 31.00 \\
\hline Self-Compassion Scale & 73.08 & 72.00 & 15.94 & 34.00 & 114.00 \\
\hline \multicolumn{7}{|c|}{ Positive and Negative Affect Schedule } \\
\hline Positive Affect & 30.71 & 31.00 & 6.91 & 11.00 & 45.00 \\
\hline Negative Affect & 25.36 & 24.00 & 7.48 & 12.00 & 45.00 \\
\hline \multicolumn{7}{|l|}{ Questionnaire of Cognitive and Affective Empathy } \\
\hline Cognitive Empathy & 59.84 & 59.00 & 7.51 & 39.00 & 76.00 \\
\hline Affective Empathy & 34.78 & 35.00 & 5.48 & 19.00 & 48.00 \\
\hline
\end{tabular}

\section{Correlations}

A correlational matrix was conducted between stress, SWB, self-compassion, and empathy (Table 2 ) to assess the nature of the relationship of the variables. The results demonstrated a significant negative relationship between stress and subjective well-being, $(r=-.69, p<.001)$. Similarly, a significant negative relationship was shown between stress and self-compassion, $(\mathrm{r}=-.59, p<.001)$. For empathy, there was a non-significant relationship between stress and cognitive empathy $(\mathrm{r}=$ $.03, p=.717$ ), but a significant positive relationship existed between stress and affective empathy, $(\mathrm{r}=.23, p=.001)$.

There was a significant positive relationship between self-compassion and subjective well-being, (r $=.57, p<.001$ ). There was also a significant negative relationship between self-compassion and affective empathy, $(r=-.22, p<.001)$, but the relationship between self-compassion and cognitive empathy was non-significant, $(\mathrm{r}=.02, p=.773)$. Lastly, there was a significant positive relationship between both subtypes of empathy, the affective and cognitive domains, $(r=.31, p<.001)$.

Table 2. Correlations between stress, subjective well-being, self-compassion, and empathy.

\begin{tabular}{|c|c|c|c|c|c|}
\hline Variables & $\mathbf{1}$ & $\mathbf{2}$ & $\mathbf{3}$ & $\mathbf{4}$ & $\mathbf{5}$ \\
\hline 1. Stress & - & & & & \\
\hline 2. SWB & $-.685^{* *}$ & - & & & \\
\hline 3. Self-Compassion & $-.586^{* *}$ & $.571^{* *}$ & - & & \\
\hline 4. Cog. Empathy & .025 & .099 & .020 & - & \\
\hline 5. Aff. Empathy & $.234^{* *}$ & -.037 & $-.223^{* *}$ & $.309^{* *}$ & - \\
\hline
\end{tabular}

Note. ${ }^{* *} \mathrm{p} \leq .01$ (2-tailed).

\section{Moderation Analysis}

To assess the effect of the predicted moderator variable (self-compassion) on the relationship between stress and SWB, a moderated regression analysis was run. An interaction term was created 
Hablado, K., \& Clark, M. (2020) A State of De-Stress: Examining the Relationship Between Subjective Well-Being, Self-Compassion, and Empathy. Advances in Social Sciences Research Journal, 7(5) 412-426

between the predictor variable (stress) and the proposed moderator variable. The analysis yielded a non-significant result for self-compassion as a moderator variable as demonstrated in Table 3.

Table 3. Regression analysis with self-compassion as a moderator variable.

\begin{tabular}{|c|c|c|c|c|c|}
\hline & Unstandardized Coefficients & \multicolumn{3}{|c|}{ Standardized Coefficients } \\
\cline { 2 - 6 } & $\mathbf{B}$ & $\mathbf{S E}$ & $\boldsymbol{\beta}$ & \multicolumn{1}{c|}{ t } & $\boldsymbol{p}$ \\
\hline Constant & -4.578 & 1.081 & & -4.234 & .000 \\
\hline Stress & -2.198 & .734 & -.571 & -2.995 & .003 \\
\hline Self-Compassion & .063 & .015 & .260 & 4.281 & .000 \\
\hline Stress*Self-Compassion & .002 & .010 & .039 & .205 & .838 \\
\hline
\end{tabular}

Dependent Variable: Subjective Well-Being

\section{Mediation Analysis}

To examine the effect of the predicted mediating variable (empathy) on the relationship between stress and SWB, a mediated regression analysis was utilized. A bivariate correlation was first run to determine whether a significant relationship existed between stress, SWB, and empathy. The results determined that there was a significant relationship between affective empathy and stress, $(\mathrm{r}=.23$, $p=.001$ ) but not for cognitive empathy ( $\mathrm{r}=.03, p=.72$ ). To assess the impact of affective empathy on the relationship between stress and subjective well-being, a partial correlation was run while controlling for affective empathy. The results determined that after controlling for affective empathy, the relationship between stress and subjective well-being remained significant $(\mathrm{r}=-.70$, $p<.001$ ), as demonstrated in Figure 1. From these results, it was deduced that neither affective nor cognitive empathy were mediator variables for the relationship between stress and subjective wellbeing.

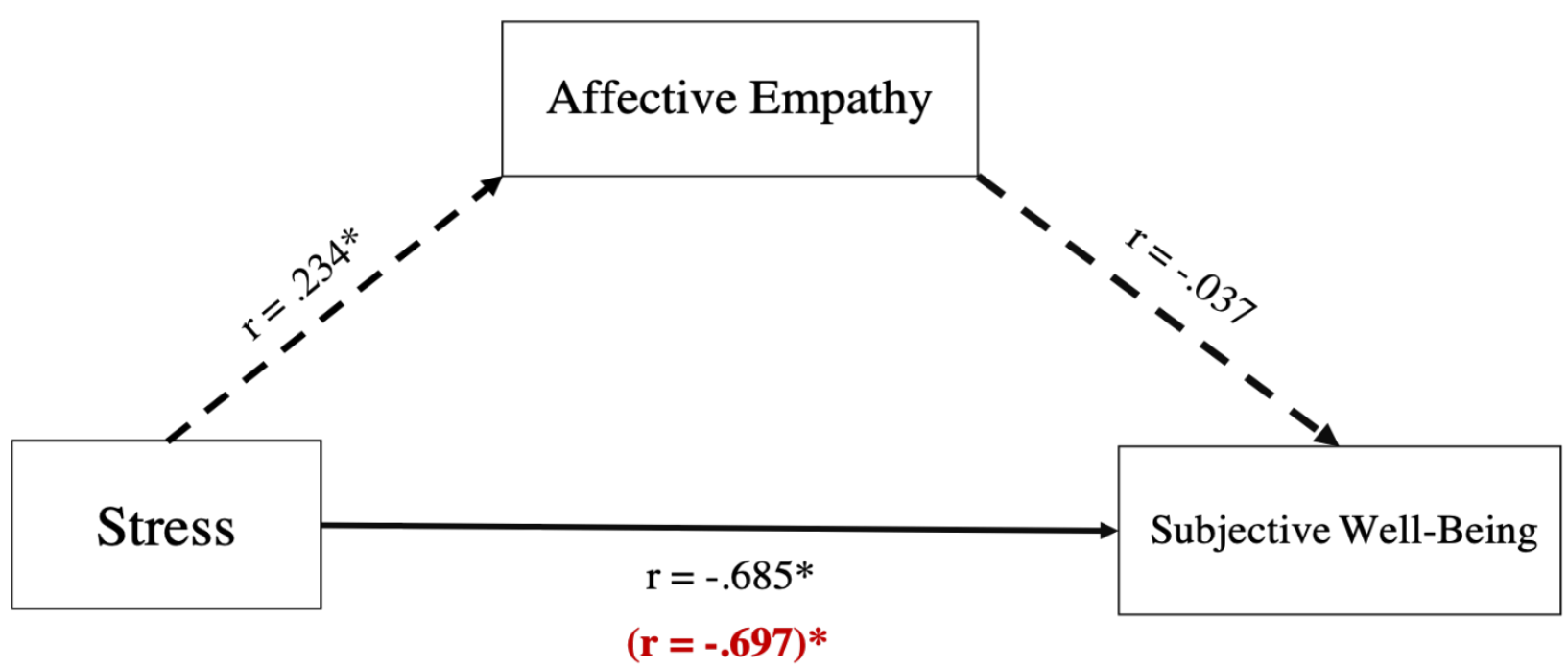

Figure 1. Reported correlations for relationships between stress, subjective well-being, and affective empathy. The reported correlation in parenthesis indicates the relationship between stress and subjective well-being after controlling for affective empathy.

Note: $* p<.001$ 


\section{Stress and Subjective Well-Being}

\section{DISCUSSION}

Previous research examining the relationship between stress and subjective well-being (Denovan \& Macaskill, 2017; Bayram \& Bilgel, 2008) has consistently found a negative relationship, and the results from the current study support that relationship. According to the results demonstrated in Table 2, one possible interpretation for this relationship is that individuals experiencing more stress will report a lower level of subjective well-being. The inverse claim is also plausible, where individuals experiencing high levels of subjective well-being will likely report lower levels of stress.

\section{Stress, Self-Compassion, and Subjective Well-Being}

The results demonstrated evidence for a significant negative relationship between stress and selfcompassion, which provided partial support for the study's first hypothesis. Despite this relationship, it was determined through a moderated regression analysis that self-compassion as a moderating variable did not significantly influence the strength of the relationship between stress and subjective well-being. In other words, responses to stress and its effect on subjective well-being cannot be predicted by the level of self-compassion that an individual possesses. One such explanation for the relationship was proposed in a meta-analysis conducted by Zessin, Dickhäuser, and Garbade (2015). Their meta-analysis of 65 articles found that self-compassion in itself may not be enough to predict well-being. In fact, a total of two potential variables were statistically significant moderators for the relationship between self-compassion and well-being - self-esteem and gender differences in overall well-being. Unfortunately, neither gender differences in levels of self-compassion nor self-esteem were examined in the present study but do offer a potential direction for future research to explore.

Another reason that self-compassion was not a significant moderator for the relationship between stress and subjective well-being could be because the stress experienced by students could be generalized as everyday irritants. Weinberger and colleagues (1987) found that everyday irritants could be more detrimental to well-being compared to a major stressful life event. In a study with UN/NATO war veterans conducted by Karlsen, Dybdahl, and Vitters $\varnothing$ (2006), it is believed that the benefits of stress (i.e. growth) develop as a result of major traumatic events. However, it could be argued that the stress caused by university occurs gradually and grows exponentially over a long period of time, so it is typically not a one-time instance. Future research could look at whether individuals have experienced a major life stressor throughout their university career (i.e. death of an important figure in their life) and examine its relationship with self-compassion to determine whether it promotes growth and acclimatization to difficulties.

\section{Stress, Empathy, and Subjective Well-Being}

With respect to the second hypothesis, the exact relationship between stress and empathy continues to be unclear. Past correlational data (Park et al., 2015; Duarte, Pinto-Gouveia, \& Cruz, 2016; Kim \& Yi, 2015) found a negative relationship existed between stress and empathy. In other words, when stress is high individuals are less likely to engage in empathy. Perhaps one explanation for these results could be attributed to where one directs their focus. For instance, individuals who are stressed are likely to be focused inwards and on themselves, and this would make it difficult to shift focus onto another person and ultimately experience empathy for that person. 
Hablado, K., \& Clark, M. (2020) A State of De-Stress: Examining the Relationship Between Subjective Well-Being, Self-Compassion, and Empathy. Advances in Social Sciences Research Journal, 7(5) 412-426.

Nonetheless, the results from the correlational matrix found a significant positive relationship between stress and affective empathy, but not with cognitive empathy. One possible speculation is that when students are experiencing high levels of stress, they are better able to understand the feelings of frustration experienced by their peers. The experimental study conducted by Wolf and colleagues (2015) reported a similar relationship between affective empathy and stress and suggested there may be a biological explanation for the results. The researchers proposed that this relationship exists because the emotional aspect of empathy is highly sensitive to stressors. By examining specific brain structures, research conducted by Blair (2005), Dziobek and research (2011), and Singer and Lamm (2009) found that the amygdala and the insula were important in the experience of emotional empathy (Wolf et al., 2015). Merz and colleagues (2010) have also found that those subcortical areas were highly sensitive to stress or the administration of cortisol (Wolf et al., 2015). Conversely, research conducted by Bahnemann and colleagues (2010), Blair (2005), and Wolf and colleagues (2010) have found that cognitive empathy is linked to the cortical regions of the brain, such as the temporo-parietal junction (Wolf et al., 2015). The researchers suggested that these brain areas were less sensitive to stress. Taken altogether, the findings posit that reactions to stress were more likely to affect our emotional empathy than our cognitive empathy. In summary, while there was a significant result between stress and affective empathy, the mediated regression model was incomplete, and empathy did not significantly explain subjective well-being.

\section{Strengths}

The results offer further support for previous research that has looked into the positive relationship between self-compassion and subjective well-being. Additionally, the research also lends support for the negative relationship that exists between stress and subjective well-being, as well as the negative relationship between stress and self-compassion. The use of correlational data established that significant relationships do exist between certain variables and this could be used to pave the way for future experimental studies that may look into cause-and-effect relationships. The research also offered certain opportunities to clarify existing, ambiguous relationships such as that between stress and empathy. Understanding the exact role of self-compassion and empathy on subjective well-being can also be used by clinicians to develop interventions that may promote both traits, which may eventually improve subjective well-being as a whole.

\section{Limitations and Future Directions}

There were a number of limitations to the study, primarily the incomplete examination of empathy as a variable. Whereas the QCAE was used to measure both the cognitive and affective aspect of empathy, it failed to account for a third aspect of empathy known as emotional regulation. According to Decety and Jackson (2006), emotion regulation is required to maintain a distinction between what the self is feeling versus what the other person is feeling. It has been suggested by Carciner and Calderón (2013) that recognizing and understanding one's own emotional state, as well as the emotional states of others, is related to an increased tolerance for stress. Specifically, this is the ability to shift focus from one's internal/emotional state onto the internal/emotional state of another individual to understand how he or she is feeling. Additionally, sole reliance on the QCAE as the only measure of empathy may have been a potential limitation due to its unreliability as a scale. Cronbach's alpha is used as a measure of internal consistency and determines the extent to which items in a certain instrument measure the same concept (Tavakol \& Dennick, 2011). Reniers and colleagues (2011) previously reported a Cronbach's alpha .65 to .85 for the QCAE, which 
indicates questionable to good internal consistency. Due to the fluctuating Cronbach's alpha values, there was a chance that certain aspects of empathy were not captured accurately. For future research, an empathy scale that measures all three aspects and has good internal consistency should be used.

Another limitation to the current research was the type of model used for the second research question. Whereas research has demonstrated existing links between stress, empathy, and subjective well-being, it is likely that the current model did not capture those relationships properly. A moderated regression analysis should be run that examines the relationship between empathy and subjective well-being, with stress as a predicted mediator variable. This would be consistent with the findings of Wei and colleagues (2011) who found a significant relationship between empathy and happiness, as well as empathy and life satisfaction in a sample of college students. As the results from the present study demonstrate a negative relationship between stress and subjective well-being, it is plausible to deduce that stress moderates the relationship between empathy and subjective well-being, when empathy is positively related to life satisfaction and happiness.

In addition, because the results of the study come from survey data, the issue of self-reporting should be considered as a possible limitation. For self-reports, Chan (2009) suggests there can be issues with the construct validity of self-report data because of the subjectivity of responses. Additionally, self-report data requires a comprehensive understanding of oneself in order to answer questions. The study uses a variety of scales that requires individuals to possess a deeper knowledge of themselves and their behaviours, such as the SCS or the QCAE. An individual must be able to understand how they act in certain situations - i.e. "I try to keep my failings as part of the human condition" (Neff, 2003a). For individuals who do not engage in introspection often, it can be difficult to ascertain whether one is accurately reporting their behaviours or not.

Finally, the results between self-compassion and stress demonstrate a negative relationship exists, but there are limitations with correlation because it cannot establish causality. Future research should look at whether self-compassion increases as a result of low stress. Or if the inverse is true, maybe stress decreases due to high levels of self-compassion. One experimental study conducted by Bluth and colleagues (2016) alluded to this relationship by exposing adolescents to stressful situations and measuring physiological responses. One direction for this research would be to follow a similar experimental model to further test whether empathy plays a similar role in mitigating the effects of stress.

\section{CONCLUSION}

The stress experienced from university has both positive and negative implications for individual growth. On the one hand, it is good to be challenged by gradually increasing academic and personal demands because it can stimulate growth. However, if those demands grow beyond the control of the individual, they may experience feelings of hopelessness or distress. The current sought to understand the role of self-compassion in mitigating the effects of stress on subjective well-being. It also sought to determine whether empathy was a possible explanation for the relationship between stress and subjective well-being. Unfortunately, there was a non-significant relationship for both variables, but the practical implications still remain. Future research should look towards 
Hablado, K., \& Clark, M. (2020) A State of De-Stress: Examining the Relationship Between Subjective Well-Being, Self-Compassion, and Empathy. Advances in Social Sciences Research Journal, 7(5) 412-426.

the development of clinical interventions that promote self-compassion or empathy as both have been previously demonstrated by research to positively correlate with subjective well-being.

\section{References}

Allen, A. B., Goldwasser, E. R., \& Leary, M. R. (2012). Self-compassion and well-being among older adults. Self Identity, 11(4), 428-453. doi:10.1080/15298868.2011.595082

Bayram, N., \& Bilgel, N. (2008). The prevalence and socio-demographic correlations of depression, anxiety and stress among a group of university students. Social Psychiatry, 43(8), 667-672.

Bluth, K., Roberson, P. N. E., Gaylord, S. A., Faurot, K. R., Grewen, K. M., Arzon, S., \& Girdler, S. S. (2016). Does selfcompassion protect adolescents from stress? Journal of Child and Family Studies, 25, 1098-1109. doi:10.1007/s10826-015-0307-3

Bourgault, P., Lavoie, S., Paul-Savoie, E., Gregoire, M., Michaud, C., Gosselin, E., \& Johnston, C. C. (2015). Relationship between empathy and well-being among emergency nurses. Journal of Emergency Nursing, 41(4), 323-328. doi:10.1016/j.jen.2014.10.001

Brazeau, C. M. L. R., Schroeder, R., Rovi, S., \& Boyd, L. (2010). Relationship between medical student burnout, empathy, and professionalism climate. Academic Medicine, 85(1), 33-36. doi:10.1097/ACM.0b013e33181ed4c47

Breines, J. G., McInnis, C. M., Kuras, Y. I., Thoma, M.V., Gianferante, D., Hanlin, L., ... Rohleder, N. (2015). Selfcompassion young adults show lower salivary alpha-amylase responses to repeated psychosocial stress. Self and Identity, 14(4), 390-402. doi:10.1080/15298868.2015.1005659

Carnicer, J. G., \& Calderón, C. (2013). Empathy and coping strategies as predictors of well-being in Spanish university students. Electronic Journal of Research in Educational Psychology, 12(1), 129-146. doi: 10.14204/ejrep.32.13117

Chan, D. (2009). So why ask me? Are self-report data really that bad. Statistical and methodological myths and urban legends: Doctrine, verity and fable in the organizational and social sciences, 309-336.

Cohen, S., Kamarack, T., \& Mermelstein, R. (1983). A global measure of perceived stress. Journal of Health and Social Behaviour, 24, 386-396.

Cooke, R., Bewick, B. M., Barkham, M., Bradley, M., \& Audin, K. (2006). Measuring, monitoring and managing the psychological well-being of first year university students. British Journal of Guidance and Counselling, 34(4), 505-517. doi:10.1080/03069880600942624

Davis, M. H. (1983). Measuring individual differences in empathy: Evidence for a multidimensional approach. Journal of Personality and Social Psychology, 44(1), 113-126. doi: 10.1037/0022-3514.44.1.113

Decety, J., \& Jackson, P. L. (2006). A social-neuroscience perspective on empathy. Current Directions in Psychological Science, 15(2), 54-58.

Denovan, A., \& Macaskill, A. (2017). Stress and subjective well-being among first year UK undergraduate students. Journal of Happiness Studies, 18(2), 505-525. doi: 10.1007/s10902-016-9736-y

Diener, E., Suh, E. M., Lucas, R. E., \& Smith, H. L. (1999). Subjective well-being: Three decades of progress. Psychological Bulletin, 125(2), 276-302.

Duarte, J., Pino-Gouveia, J., \& Cruz, B. (2016). Relationships between nurses' empathy, self-compassion and dimensions of professional quality of life: A cross-sectional study. International Journal of Nursing Studies, 60, 1-11.

Dwyer, A. L., \& Cummings, A. L. (2001). Stress, self-efficacy, social support, and coping strategies in university students. Canadian Journal of Counselling, 35(3), 208-220.

Finlay-Jones, A. M., Rees, C. S., \& Kane, R. T. (2015). Self-compassion, emotion regulation and stress among Australian psychologists: Testing an emotion regulation model of self-compassion using structural equation modeling. PLOS ONE, 10(7), 1-19. doi:10.1371/journal.pone.0133481 
Friedlander, L. J., Reid, G. J., Shupak, N., \& Cribbie, R. (2007). Social support, self-esteem, and stress as predictors of adjustment to university among first-year undergraduates. Journal of College Student Development, 48(3), $259-274$. doi: 10.1353/csd.2007.0024.

Huebner, E. S. (1991). Initial development of the Students' Life Satisfaction Scale. School Psychology International, 12, 231-243.

Karlsen, E., Dybdahl, R., \& Vitters $\varnothing$, J. (2006). The possible benefits of difficulty: How stress can increase and decrease subjective well-being. Scandinavian Journal of Psychology, 47, 411-417. doi:10.1111/j.1467-9450.2006.00549.x

Kim, H., \& Yi, M. (2015). Factors influencing empathy in nursing students in Korea. The Journal of Korean Academic Society of Nursing Education, 21(2), 237-245.

Leary, M. R., Tate, E. B., Adams, C. E., Allen, A. B., \& Hancock, J. (2007). Self-compassion and reactions to unpleasant self-relevant events: The implications of treating oneself kindly. Journal of Personality and Social Psychology, 92(5), 887-904. doi:10.1037/0022-3514.92.5.887

Lee, E. (2012). Review of the psychometric evidence of the Perceived Stress Scale. Asian Nursing Research, 6, 121-127. Myers, D. G., \& Diener, E. (1995). Who is happy? Psychological Science, 6(1), 10-19. doi: 10.1111/j.14679280.1995.tb00298.x

Neely, M. E., Schallert, D. L., Mohammed, S. S., Roberts, R. M., \& Chen, Y. (2009). Self-kindness when facing stress: The role of self-compassion, goal regulation, and support in college students' well-being. Motivation and Emotion, 33(1), 88-97. doi: 10.1007/s11031-008-9119-8

Neff, K. D. (2003a). The development and validation of a scale to measure self-compassion. Self and Identity, 2, 223250. doi:10.1080/15298860390209035

Neff, K. D. (2003b). Self-compassion: An alternative conceptualization of a healthy attitude toward oneself. Self and Identity, 2, 85-101. doi: 10.1080/15298860390129863

Neff, K. D., Kirkpatrick, K. L., \& Rude, S. S. (2007). Self-compassion and adaptive psychological functioning. Journal of Research in Personality, 41, 139-154.

Park, K.H., Kim, D., Kim, S. K., Yi, Y. H., Jeong, J. H., Chae, J., ... Roh, H. (2015). The relationship between empathy, stress and social support among medical students. International Journal of Medical Education, 6, 103-108. doi:10.5116/ijme.55e6.0d44

Reniers, R. L. E. P., Corcoran, R., Drake, R., Shryane, N. M., \& Völlm, B. A. (2011). The QCAE: A questionnaire of cognitive and affective empathy. Journal of Personality Assessment, 93(1), 84-95. doi:10.1080/00223891.2010.528484

Shanafelt, T. D., West, C., Zhao, X., Novotny, P., Kolars, J., Habermann, T., \& Sloan, J. (2005). Relationship between increased personal well-being and enhanced empathy among internal medicine residents. Journal of General Internal Medicine, 20, 559-564. doi:10.1111/j.1525-1497.2005.0108.x

Stallman, H. M. (2008). University Stress Scale. Brisbane: Queensland University of Technology.

Stallman, H. M., \& Hurst, C. P. (2016). The University Stress Scale: Measuring domains and extent of stress in university students. Australian Psychologist, 51(2), 128-134.

Tavakol, M., \& Dennick, R. (2011). Making sense of Cronbach's alpha. International Journal of Medical Education, 2, 5355.

Thoma, P., Zalewski, I., von Reventlow, H. G., Norra, C., Juckel, G., \& Daum, I. (2011). Cognitive and affect empathy in depression linked to executive control. Psychiatry Research, 189, 373-378. doi:10.1016/j.psychres.2011.07.030

Thomas, M. R., Dyrbye, L. N., Huntington, J. L., Lawson, K. L., Novotny, P. L., Sloan, J. A., \& Shanafelt, T. D. (2007). How do distress and well-being relate to medical student empathy? A multicenter study. Society of General Internal Medicine, 22, 177-183.

Watson, D., Clark, L. A., \& Tellegen, A. (1988). Development and validation of brief measures of positive and negative affect: The PANAS. Journal of Personality and Social Psychology, 54(6), 1063-1070. 
Hablado, K., \& Clark, M. (2020) A State of De-Stress: Examining the Relationship Between Subjective Well-Being, Self-Compassion, and Empathy. Advances in Social Sciences Research Journal, 7(5) 412-426.

Wei, M., Liao, K. Y., Ku, T., \& Shaffer, P. A. (2011). Attachment, self-compassion, empathy, and subjective well-being among college students and community adults. Journal of Personality, 79(1), 191-221. doi:10.1111/j.14676494.2010.00677.x

Welp, L. R., \& Brown, C. M. (2014). Self-compassion, empathy, and helping intentions. Journal of Positive Psychology, 9(1), 54-65. doi:10.1080/17439760.2013.831465

Wolf, O. T., Schulte, J. M., Drimalla, H., Hamacher-Dang, T. C., Knoch, D., \& Dziobek, I. (2015). Enhanced emotional empathy after psychosocial stress in young healthy men. Stress, 18(6), 631-637.

Zessin, U., Dickhäuser, O., \& Garbade, S. (2015). The relationship between self-compassion and well-being: A metaanalysis. Applied Psychology: Health and Well-Being, 7(3), 340-364.

Zhong, L. F. (2009). Academic stress and subjective well-being: The moderating effects of perceived social support. Industrial Engineering and Engineering Management, 1321-1324. doi:10.1109/ICIEEM.2009.53444 